\title{
0 poder simbólico e o gerenciamento de impressões em organizações públicas: a construção do mito da eficácia do Banco Central na administração da política econômica
}

\author{
Paulo José de Castro Jatahi *
}

\begin{abstract}
Resumo
0 gerenciamento de impressões tem sido utilizado pelas organizações como um poderoso instrumento para aquisição de recursos do ambiente em que estão inseridas. Dessa perspectiva, atuar sobre a imagem organizacional de forma a gerar impressões positivas nos componentes do ambiente representa legitimar as atividades da organização junto ao público que dá suporte aos seus objetivos e às suas ações. Este artigo busca situar o gerenciamento de impressões na linha dos estudos sobre o poder e os elementos simbólicos do contexto organizacional. Tomando o Banco Central do Brasil (Bacen) como exemplo de organização pública que reconhece e emprega o gerenciamento de impressões na administração do sistema financeiro nacional, o objetivo é identificar na atuação dessa instituição os elementos que configuram essa perspectiva.
\end{abstract}

Palavras-chave: gerenciamento de impressões; poder; simbolismo.

\begin{abstract}
Impression management has been used by organizations as a powerful tool to get resources from the environment they belong. In this perspective, an organization that shapes its image in a way it creates positive impressions to the other environment components, is in fact legitimating its activities by people that support the organization goals and actions. This article addresses impression management as a part of the studies on power and other symbolic elements of the organizational environment. Taking the Central Bank of Brazil as an example of a public organization that recognizes and uses these techniques on the management of the national financial system, this paper identifies the main elements of this perspective on the organization trades.
\end{abstract}

Keywords: impression management; power; symbolism.

\section{Introdução}

As organizações contemporâneas tendem a se relacionar com o ambiente em que estão inseridas, de forma cada vez mais complexa. A incerteza gerada pelo ambiente econômico globalizado, que caracteriza este novo tempo, faz com que os esforços produtivos se direcionem para práticas consagradas por outras organizações, ou impostas pela sociedade e governo, ou mesmo ditadas pela cultura de seus profissionais, em movimentos isomorfos que muitas vezes superam o puro objetivo econômico. A liderança desses processos é vista como inovadora e pode proporcionar ganhos estratégicos importantes para as empresas, no campo organizacional específico a que pertencem. Nesse contexto, é valorizada a capacidade de uma empresa utilizar recursos simbólicos, na consolidação de uma cultura organizacional que apoie a estratégia empresarial.

Apesar das peculiaridades, as organizações públicas também estão sensíveis a essas tendências, e têm procurado desenvolver habilidades simbólicas em seus quadros. O Banco Central do Brasil (Bacen) acumulou, no período de estabilização que se seguiu ao Plano Real, um considerável reconhecimento da sociedade, pela condução eficaz da política econômica do país. Este artigo procura relacionar a construção do mito da autoridade monetária eficaz que o Banco Central detém, com a utilização consciente ou inconsciente de recursos simbólicos pelos seus agentes. Com esse objetivo, inicialmente, é apresentada uma revisão dos estudos

* Mestrado em Administração Pública pela EBAPE/FGV. E-mail: pjatahy@ yahoo.com.br.

Artigo recebido em março de 2004 e aceito em maio de 2004. 
organizacionais sobre simbolismo, poder e poder simbólico, para se estabelecer, em seguida, uma relação dos aspectos dessas narrativas com os observáveis na ação do banco, na construção de sua imagem institucional.

\section{0 simbolismo nos estudos organizacionais}

A partir de meados da década de 1970, os estudos organizacionais passaram a dedicar maior atenção aos aspectos culturais e simbólicos, como importantes fatores de desenvolvimento das estruturas e dos ambientes das organizações. Embora Durkheim (1999) e Weber (1997) já tivessem contribuído significativamente, com suas análises sociológicas das organizações, é na década de 1980 que a vertente cultural se populariza, com diversos trabalhos produzidos, que buscavam explicar as relações entre os elementos constituintes da organização, através da interação entre esquemas cognitivos internalizados por cada um. Os principais expoentes dessa corrente são os institucionalistas, que a partir dos trabalhos de Selznick (1949 e 1957), passam a entender a organização pelas expressões de valor compartilhadas, em lugar das expressões de racionalidade técnica.

O simbolismo organizacional pode ser entendido como a expressão "dos aspectos de uma organização que seus membros costumam usar para mostrar ou tornar compreensíveis os sentimentos inconscientes, imagens e valores inerentes à organização" (DANDRIDGE, MITROFF e JOYCE, 1980). Esses aspectos se manifestam através das tradições, dos mitos, rituais, imagens e jogos de poder, que são construídos e perpetuados em diferentes graus na estrutura de relacionamentos criada entre os membros da organização. Os símbolos falam ao inconsciente do indivíduo, ao significado de sua existência. "Toda sociedade parece natural a seus membros à medida que, pela adesão a seus símbolos e pela confiança em seus padrões, sintam eles a própria existência como alguma coisa que se harmoniza com aquela ordem" (RAMOS, 1982). Os símbolos operam entre a realidade e o inconsciente, e seus estudiosos identificam entre suas funções a mediação entre essas dimensões, permitindo a construção de pontes entre elas; seja pela socialização, através da comunicação entre os membros do grupo que compartilham os mesmos valores; seja pela via pedagógica e terapêutica, integrando o homem ao universo e ao mesmo tempo causando medo e gerando segurança (equilíbrio psicossocial); como também pela transcendência, unindo e harmonizando forças antagônicas.

No quadro 1 é proposto uma tipologia de simbolismo organizacional:

\section{Quadrol}

Funções e tipos de simbolismo organizacional

\begin{tabular}{|c|c|c|c|}
\hline \multicolumn{2}{|c|}{ Funções do simbolismo } & \multicolumn{2}{|c|}{ Tipos de simbolismo organizacional } \\
\hline Descritiva & $\begin{array}{l}\text { - provê uma expressão da } \\
\text { organização }\end{array}$ & Verbal & $\begin{array}{l}\text { - mitos, lendas, histórias, } \\
\text { slogans, credos, piadas, } \\
\text { rumores, denominações }\end{array}$ \\
\hline $\begin{array}{l}\text { Controle de } \\
\text { energias }\end{array}$ & $\begin{array}{l}\text { - inspira membros } \\
\text { - atrai recrutas } \\
\text { - repele outsiders } \\
\text { - facilita reexperimentar } \\
\text { sentimentos } \\
\text { - reduz a tensão } \\
\text { - provê válvulas de escape }\end{array}$ & Ação & $\begin{array}{l}\text { - rituais, festas, ritos de } \\
\text { passagem }\end{array}$ \\
\hline $\begin{array}{l}\text { Conservadora } \\
\text { do sistema }\end{array}$ & $\begin{array}{l}\text { - provê coerência, ordem e } \\
\text { estabilidade } \\
\text { - integra e diferencia } \\
\text { - provê guias para padrões } \\
\text { de mudanças }\end{array}$ & Material & $\begin{array}{l}\text { - símbolos de status, } \\
\text { logotipos, prêmios, } \\
\text { bandeiras }\end{array}$ \\
\hline
\end{tabular}

Fonte: Wood, 2001, adaptado de Dadridge, Mitroff \& Joyce, 1980. 
Em oposição à teoria de sistemas e ao "contingencialismo" predominantes desde a década de 1960 - que propunham uma compreensão homogênea da realidade e das relações, fundadas no racionalismo -, e tendo o ambiente como fonte de recursos e "depósito" de resultados do processamento das atividades organizacionais, o institucionalismo e outras correntes apoiadas na compreensão da simbologia cultural contextualizam a sociedade como "um meio em contínua reinterpretação da realidade e das relações, a partir de redes subjetivas criadas e recriadas por meio da troca de recursos entre seus membros" (WOOD, 2001). Nesse contexto, o ambiente passa a representar o conjunto de elementos que fornece as crenças que constituem os chamados "mitos racionais", sistema de crenças e normas do ambiente que garante condições para o surgimento das organizações e o desenvolvimento de suas estruturas e atividades (SCOTT, 1992).

A construção desse sistema de crenças e normas está ligada ao conjunto de ações simbólicas desenvolvidas nas organizações e às relações de poder construídas entre seus membros. Calás e MacGuire (1990) identificam seis atividades simbólicas e de poder, cujos sistemas de significados seriam constantemente renovados e explicariam a organização:

- a distinção, ou seja, a construção de uma identidade simbólica pelo grupo, através da adoção de mitos e rituais;

- a comunicação, que representa a troca de mensagens e o "compartilhamento" de seus significados entre os membros;

- a tomada de decisão, ou seja, a ação desenvolvida a partir de padrões de procedimento;

- o exercício da autoridade e da liderança, que corresponde ao estímulo mútuo entre líderes e liderados, num processo de ampla manipulação de símbolos;

- a integração orgânica de mitos, normas e valores, formando a ideologia; e

- a socialização, através da promoção de cerimônias freqüentes para manter o sistema vivo.

Os estudos mostram que a dimensão simbólica das organizações está intimamente ligada ao contexto em que o poder e a autoridade são exercidas, e que se alimenta da comunicação e interação simbólicas como forma de desenvolvimento.

\section{Poder nos estudos organizacionais}

Diferentemente da cultura e dos símbolos, o poder sempre foi tratado como uma questão central nos estudos dos fenômenos sociais. Desde Platão e Aristóteles, o poder, como forma de expressão da vontade do povo, tem sido objeto de discussões que enfatizam os aspectos mais caros a cada período histórico. Num primeiro momento, o poder foi enfocado como uma forma de realização coletiva, que não implica perda para os indivíduos, mas uma possibilidade de todos ganharem. Essa concepção ressalta os benefícios e o aspecto comunal do poder, em que o cidadão se empenha na participação ativa e constante no poder coletivo. $\mathrm{O}$ desenvolvimento das estruturas políticas, desde a Grécia Antiga, até o advento das repúblicas, foi construído segundo esse concepção, em que o poder se legitima pela aceitação de todos, sem a existência de conflito.

$\mathrm{Na}$ evolução do pensamento clássico, essa concepção ganhou contornos mais hierárquicos, que associavam o poder à ordem e à liberdade. Na definição de Voltaire, citada por Lukes (1983), "o poder consiste em fazer os outros agirem como eu quero", constituindo-se num poder real. Já Hobbes acreditava que o poder é potencial, quando afirmou que "o poder de um homem é seu meio presente de obter algum bem futuro evidente" (apud LUKES, 1983). Essa diferença é relevante para reconhecermos que indivíduos com a mesma quantidade de recursos de poder podem exercer diferentes graus de influência, por utilizarem seus recursos de modos diferentes (VIEIRA e MISOCZKY, 2000). Saber combinar esses recursos de forma a produzir poder efetivo, resultante do poder potencial convertido em poder real, é administrar significados.

Entre os autores contemporâneos, destacam-se Arendt (1994), para quem o poder "não se baseia na relação de mando e obediência", e sim na capacidade humana de agir em concerto; e Parsons (1960), que vê o poder como 
um recurso dentro de um sistema de organização coletiva capaz de mobilizar os recursos da sociedade para a consecução de metas, atendendo a um compromisso público geral.

A chave para o entendimento do poder como fenômeno consensual está em sua legitimação, o que na visão de Parsons é conferida, à semelhança política, por um mandato, que dá a seu detentor direitos, mas também obrigações em relação àqueles que lhe estão sujeitos. A legitimação do poder tem conteúdo simbólico, já que o reconhecimento da autoridade da qual deriva é um mito institucionalizado, que permite a seus detentores demandar o reconhecimento pelos demais.

As idéias de Parsons são a expressão contemporânea de uma linha de pensamento que considera a ordem social constituída pelas convicções comuns, provenientes em sua maioria da autoridade exercida sobre a crença, como classifica Lukes (1983). Nesse sentido, o poder é considerado como oriundo da autoridade,

"mas também como uma ameaça quando abusado, de forma a enfraquecer ou destruir as crenças consensuais e com isso a ordem social e política. Em condições consensuais, o poder tende a assumir a forma não-assimétrica, não conflituosa, pelo menos internamente à sociedade em questão, e a noção de liderança é enfatizada. (...) Os conflitos de interesses entre indivíduos e grupos, pelo menos numa sociedade que funciona bem, não são ressaltados - em parte porque a própria existência da autoridade cria e promove, ao que se acredita, uma identidade de interesses entre os que a exercem e os que a ela estão sujeitos" (LUKES, 1983).

O poder também pode ser visto como uma forma de dominação, imposta por um grupo aos demais indivíduos. Constitui assim uma relação assimétrica, em que seu exercício implica redução do poder dos outros. Pressupõe o conflito e a resistência, embora a autoridade da qual é emanado possa ser estabelecida por convenção, ou seja, do consentimento de indivíduos com interesses conflitantes (LUKES, 1983). Novamente é mencionada a legitimação, que servirá como base para o exercício do poder simbólico. Mesmo considerando o conflito e a resistência, a estrutura de relações de poder numa sociedade está completamente legitimada por um sistema de suposições culturais e normativas. Os atores dominantes se utilizam do gerenciamento de significados para, numa estratégia de legitimação, se prevenirem de um desafio ao poder existente (VIEIRA e MISOCZKY, 2000).

Weber foi um dos expoentes dessa corrente, e suas definições são significativas para entendermos as diferenças entre estes conceitos:

"Poder significa a probabilidade de impor a própria vontade, dentro de uma relação social, ainda que contra toda a resistência e qualquer que seja o fundamento dessa probabilidade. Por dominação deve-se entender a probabilidade de encontrar obediência a um mandato de determinado conteúdo entre pessoas dadas; por disciplina deve-se entender a probabilidade de encontrar obediência a um mandato, por parte de um conjunto de pessoas que, em virtude de atitudes arraigadas, seja rápida, simples e automática" (WEBER, 1997, p.43).

Hardy e Clegg (1999) sustentam que mesmo entre os que identificam o conflito como intrínseco ao exercício do poder, há divergências no enfoque adotado, formando duas correntes que "raramente se comunicam entre si": a crítica, que tem o poder como "construto" central da ação coletiva, e a funcionalista, com uma orientação gerencialista, em que o poder é aceito como normal, inevitável e derivado da estrutura formal da organização.

A corrente crítica, apoiada nos trabalhos de Marx e Weber sobre poder, desenvolveu os temas da dominação e exploração dos indivíduos, e do conflito de interesses entre aqueles sobre os quais o poder é exercido e aqueles a que serve. Essas formulações derivam das relações de propriedade e controle dos meios de produção que deram origem às estruturas de classe, onde de um lado temos a classe dominante, que detém o capital, e do outro, os que possuem apenas suas capacidades disciplinadas, ofertadas no mercado de trabalho. Diferentemente de Marx, que restringia as capacidades disciplinadas de trabalho à propriedade dos meios de produção, Weber reconhecia as capacidades derivadas do conhecimento, abrindo espaço para os membros da organização exercerem o poder, desafiando-o ou reproduzindo estruturas formais, e tornando esse poder menos 
dependente da força econômica. Essa capacidade de exercício de poder está ligada ao discernimento que o trabalhador tenha dele, e nesse contexto, a gerência busca "estratégias e táticas que obscureçam o discernimento dos trabalhadores" (HARDY e CLEGG, 1999, p.263).

Uma tendência da corrente crítica tem sido a reinterpretação dos sistemas de regras da burocracia weberiana, sob a influência do poder disciplinar derivado de Foucault (1977). O poder disciplinar surge, segundo Foucault, do reconhecimento do poder de Estado como poder social, ocorrido no século XVIII, e consiste na disseminação, pela normalização das subjetividades, do controle do comportamento dos indivíduos. A institucionalização das ciências humanas e sociais é que alavanca a disseminação desse poder invisível, não intencional e onipresente, caracterizado pela vigilância permanente, exercida anonimamente pelas práticas e estruturas das organizações.

"A ação sobre o corpo, o controle do gesto, a regulação do comportamento, a normalização do prazer e a interpretação do discurso (com o objetivo de separar, comparar, avaliar, hierarquizar) fazem com que o homem apareça como produto do poder e, ao mesmo tempo, como objeto do saber" (VIEIRA e MIZOCZKY, 2000).

A concepção funcionalista do poder, apesar de aceitar o conflito derivado de seu exercício, situa-o como disfuncional ou ilegítimo, ou seja, ao classificar o poder derivado da estrutura hierárquica das organizações como legítimo, considera ilegítimo "o poder exercido fora das estruturas hierárquicas formais e dos canais sancionados por estas estruturas" (HARDY e CLEGG, 1999). A linha dos estudos filiados a essa concepção busca examinar como diversos grupos adquirem e mantêm um poder não concedido a eles dentro dos formatos oficiais.

Diversas teorias se desenvolveram seguindo essa concepção: das abordagens sistêmicas de Thompson (1956), Bennis (1958) e Crozier (1981), que identificaram a existência de uma estrutura de poder informal dentro da formal, derivada do domínio que certos trabalhadores tinham sobre as fontes de incerteza que permaneciam fora do controle burocrático - a capacidade de controlar a incerteza é fonte potencial de poder -, passando pela teoria das contingências estratégicas, que produziu um modelo funcionalista formal, descrevendo a organização como um sistema de subunidades funcionais interdependentes - subunidades estrategicamente contingentes têm mais poder, pois são menos dependentes das demais e podem sobreviver numa situação de incerteza sistêmica - até chegar na teoria da dependência de recursos. Esta identifica a posse, o controle e o uso de recursos como informação, especialidade técnica, incerteza, recompensas e sanções, como bases de poder, prevalecendo a idéia de que mobilizar poder fora dos arranjos formais é ilegítimo ou disfuncional.

Mais recentemente, o foco da literatura funcionalista tem se voltado para o uso do poder visando vencer o conflito, em oposição aos críticos contemporâneos, que têm se dedicado a formas de exercício de poder que visam evitar o conflito. Os críticos desenvolviam visões alternativas de poder, como Bachrach e Baratz (1970), que criticam os pluralistas pela suposição de igual acesso às arenas e agendas de decisão, desenvolvendo a tese do controle pelos grupos mais poderosos da agenda política, através da supressão de temas inconvenientes do processo decisório (a não participação ou não decisão); ou como Lukes (1983) e o emprego do poder para moldar percepções, cognições e preferências, de tal modo que ele seja aceito (ou legitimado), através de um sistema de suposições culturais e normativas. Os funcionalistas tratavam a atividade política como aquela desenvolvida para superar resistência ou oposição, o que, na sua ausência, não se justificava (PFEFFER,1981). Vinculam-se assim à visão do poder como força necessária a sobrepujar a oposição de grupos ilegítimos (na acepção de grupos não sancionados pela autoridade formal e pela ideologia aceita, nem por uma especialidade reconhecida (MINTZBERG, 1983)), exercido pelas elites organizacionais. A principal crítica à perspectiva funcionalista é que a aceitação das estruturas de poder embricadas no desenho formal da organização, sem questionar se os objetivos ditos organizacionais não se confundem com os interesses individuais da alta gerência, é subestimar potenciais abusos de poder pelos grupos dominantes e assumir postura conservadora que implicitamente defende o status quo dos dominadores. 


\section{0 poder simbólico e o gerenciamento de impressões}

Os estudos organizacionais se aproximam do reconhecimento dos valores individuais na construção da realidade dos grupos sociais. No campo político e social, essa reconciliação dos ideais de individualidade com a existência de uma autoridade baseada no consenso começou com Rousseau e seu Contrato social, e com Hegel, dando forma à idéia de que o Estado representa a união da consciência subjetiva dos indivíduos com a ordem objetiva, num acordo que proteja os direitos individuais e dê continuidade aos interesses conflitantes dos indivíduos (LUKES, 1983). A evolução do contrato de vontades racionais unidas se dá dentro do paradigma modernista da crença no aperfeiçoamento da humanidade através do pensamento racional e no consenso, "a harmonia mecânica entre atores interagindo funcionalmente" (BURRELL e COOPER, 1988). O desenvolvimento dos elementos simbólicos do poder nas organizações ocorre predominantemente nas construções pós-modernas, que criticam o racionalismo e o consenso, enfatizando as subjetividades e o dissenso como espaço propício para a criatividade (LYOTARD, 1998).

Os primeiros estudos a valorizar elementos simbólicos estavam ligados à criação de legitimidade, como forma de evitar formas mais coercitivas e visíveis de poder. A corrente funcionalista tentou catalisar, através do gerenciamento de significados, habilidades para que a dominação gerencial fosse percebida como legítima: "o gerenciamento de significados relaciona-se com um processo de construção de símbolos e de uso de valores, concebidos tanto para criar legitimidade para nossas demandas como para 'deslegitimar' as demais" (PETTIGREW, 1977). No entanto, a maioria dos pesquisadores filiados a essa corrente subestimou o uso do poder simbólico, vendo-o apenas como ferramenta acessória no processo de legitimação de resultados já alcançados pela dependência de recursos (LUKES, 1983).

Hardy e Clegg (1999) consideram necessário compreender a natureza multivalente das formas de poder nas organizações, pois as pessoas nelas inseridas manifestam significados específicos de acordo com as múltiplas identidades incorporadas de modo organizacional, baseadas em etnicidade, gênero, classe social, idade e outros. Como consequiência das formas de dominação estabelecidas com base nessas identidades, são criadas divisões de trabalho sujeitas a complexas teias de relações de poder. Nas disputas de poder e resistência que se estabelecem, "a ênfase é no jogo de símbolos, significações e ações, por meio dos quais todos os atores organizacionais tentam escrever, dirigir e posicionar todos os demais" (HARDY e CLEGG, 1999).

Bourdieu (2000) é quem eleva o simbolismo no estudo do poder à sua posição central, observando que

"num estudo do campo em que se vê o poder por toda a parte, como em outros tempos não se queria reconhecê-lo nas situações em que ele entrava pelos olhos dentro, não é inútil lembrar que (...) é necessário saber descobri-lo onde ele se deixa ver menos, onde ele é mais completamente ignorado, portanto reconhecido: o poder simbólico é, com efeito, esse poder invisível, o qual só pode ser exercido com a cumplicidade daqueles que não querem saber que lhe estão sujeitos ou mesmo que o exercem".

Bourdieu substitui a noção de sociedade e de classes pelo relacionamento entre estruturas objetivas (campos sociais e espaço social) e estruturas subjetivas (esquemas de percepção, pensamento e ação constitutivos do "habitus"), com base nos seguintes pressupostos fundamentais:

- os sistemas simbólicos são estruturantes e só podem sê-los por serem estruturados - o poder simbólico é um poder de construção da realidade que tende a estabelecer uma ordem gnosiológica, ou seja, que dá um sentido imediato de mundo; e

- os instrumentos simbólicos são formas de dominação que representam os interesses de um grupo dominante, no sentido de adotar um sistema de valores que passa a ser socialmente legitimado através de processos ideológicos.

O conceito de "habitus" se refere ao capital social dos agentes, ao conjunto de ferramentas simbólicas adquiridas no tempo pelos indivíduos, sob a forma de esquemas mentais e corporais de percepção, compreensão e ação. 
O campo é um espaço, empiricamente delimitado e socialmente estruturado, com seus próprios princípios reguladores, onde os agentes atuam no sentido de aumentar ou conservar seu capital (o "habitus"), em conformidade com essas regras, ou mesmo no sentido de alterar as regras ou a distribuição e o peso relativo, ou a taxa de conversão entre os diferentes tipos de capital.

O campo político é formado pelo conjunto de forças que disputam o capital social através da manipulação simbólica da vida social. Dessa forma, o controle dos significados sociais seria a principal fonte de poder dentro do campo. Os conceitos são gerados por um grupo dominante dentro de um determinado campo intelectual, representado pelos profissionais, indivíduos conhecedores das regras do jogo político e detentores do habitus necessário à participação no jogo. Por outro lado, as disputas ocorridas no campo dependem do nível em que os discursos políticos obtêm adesão por parte dos "leigos", ou seja, aqueles indivíduos ou instituições que estão fora do campo profissional, mas que formam o capital social necessário para legitimar os conceitos vigentes na vida social (VIEIRA, CARVALHO e LOPES, 2001).

O espaço social é composto por um conjunto de campos políticos, onde ocorrem as disputas pela hegemonia do poder social.

O campo de poder é fundamental para compreender as relações entre os agentes nos diversos campos sociais e como o poder se reproduz. Segundo Bourdieu (1996)

"O campo do poder é um campo de forças estruturalmente determinado pelo estado das relações de poder entre tipos de poder, ou diferentes tipos de capital. Também é, de modo inseparável, um campo de lutas de poder entre os detentores de diferentes formas de poder, um espaço de jogo em que aqueles agentes e instituições possuidores de suficiente capital específico são capazes de ocupar posições dominantes dentro de seus campos respectivos, e confrontar os demais, utilizando estratégias voltadas para preservar ou transformar as relações de poder. Os tipos diferentes de capital são tipos específicos de poder que são ativos em um ou outro campo (de forças e lutas) gerados no processo de diferenciação e autonomização. Dentro desses diferentes espaços de jogo surgem tipos característicos de capital que são, simultaneamente, instrumentos e objetos de disputa" (BOURDIEU, 1996, p.265).

A motivação para as disputas internas nos campos sociais é ligada aos interesses em jogo. Os interesses são socialmente constituídos e apenas existem na relação com um espaço social, no qual algumas coisas são relevantes e outras indiferentes para os agentes. Essas disputas de interesse são guiadas por condutas não necessariamente ditadas pela razão, não guiadas por fins. Existe uma relação de cumplicidade infraconsciente entre o agente e o mundo social, entre o "habitus" e o campo (MISOCZKY, 2002).

Essa influência dos ambientes na definição e comportamento das organizações também foi salientada nas formulações institucionalistas. A abordagem institucional enfatiza a dependência ambiental da estrutura organizacional, as dimensões política e cultural envolvidas e os efeitos dessas dependências no desenvolvimento de uma natureza fluída e complexa das organizações criadas em ambientes altamente institucionalizados (SCOTT e MEYER, 1994). Nessa abordagem, os ambientes passam a ser tratados não apenas como fonte de recursos e depósito de resultados do processamento das atividades organizacionais, mas como um grupo de elementos que fornecem as crenças que funcionam como "mitos racionais".

Em suas variantes reguladora, normativa ou cognitiva, a abordagem institucional busca nas diversas formas culturais - normas e leis, expectativas ou tipificações, segundo a variante -, nas estruturas sociais - sistemas de poder, de autoridade ou isomorfismo estrutural, conforme a versão - e nas atividades rotineiras do cotidiano da organização - procedimentos padronizados, conformidade ou execução de programas de ação, de acordo com a versão reguladora, normativa ou cognitiva -, elementos institucionais que expliquem a organização (SCOTT, 1995a). A versão cognitiva, predominante no Novo Institucionlismo de Meyer, DiMaggio, Scott, Powell e Rowan sublinha o papel dos processos cognitivos e sistemas simbólicos, propondo interpretações subjetivas das ações dos indivíduos em relação às representações que estes fazem de seus ambientes. "O estímulo do ambiente deve ser cognitivamente processado pelos atores - interpretado pelos indivíduos, empregando sistemas simbólicos socialmente construídos - antes que possam reagir" (SCOTT e CHRISTENSEN, 1995b). 
Embora o nível de análise no institucionalismo seja preferencialmente o societário e o organizacional, é no nível grupal e individual que vemos algumas características da operacionalização dos artefatos simbólicos. Assim, no desenvolvimento dos jogos de poder no interior das organizações, sobressai a liderança simbólica, que envolve fenômenos grupais e processos de influência conduzidos não exclusivamente pelo líder, mas construídos na interação entre líder e liderados. "Líderes e liderados são parceiros e cúmplices na encenação do mito da liderança" (WOOD, 2001).

Liderança, segundo Smircich e Morgan (1982), é o processo pelo qual um ou mais indivíduos definem a realidade para outros indivíduos, e é efetiva quando o líder consegue articular a experiência e os sentidos compartilhados pelo grupo, de forma a viabilizar determinados modos de ação. Assim, a liderança pode ser vista como um processo simbólico de criação de imagens e definição de significados que ocorre por meio da interação entre os diversos atores envolvidos, compreendendo ações de interpretação, estruturação e transformação da realidade.

Os líderes se engajam em transformar situações complexas e ambíguas em questões solúveis, criando pontos de referência e esquemas interpretativos para facilitar o atendimento dos objetivos organizacionais. São capazes de compreender rapidamente a dinâmica organizacional, e agem fazendo uso de símbolos, metáforas, retórica e imagens, num processo de intervenção contínua na rede de significados. Cultuam a imagem de executivo eficaz que criam para si, a partir da manutenção de uma aparência de controle e domínio sobre as situações complexas. Ao interpretarem a realidade e realizarem diagnósticos, realimentam seu próprio mito, o que pode servir a interesses pessoais e levá-los a uma supersimplificação da realidade ambiental e a uma idealização da sua própria capacidade.

Uma das principais tarefas da liderança simbólica nos ambientes complexos é o gerenciamento de impressões. Ramos (1982) identificava no formalismo que caracteriza a conduta humana na sociedade centrada no mercado - onde a observância das regras substitui a preocupação com padrões éticos substantivos -, um traço de reconhecimento da adequação do comportamento, pelo grupo. Nesse contexto, para conquistar a aceitação, o líder passa a administrar a imagem que produz nos outros, o que é a gerência das impressões.

Wood (2001) define o gerenciamento de impressões como "a arte de projetar e executar uma determinada forma de comunicação ou interação, de modo que a audiência - externa ou interna - chegue a conclusões ou comportamentos planejados". Esse autor afirma que as organizações estão permanentemente envolvidas com as atividades de gerenciamento de impressões, tendo como audiência não só o público em geral, mas também outras corporações, funcionários, consumidores, governo e outros atores significativos que possam influenciar seu desempenho. Os institucionalistas identificariam essa prática como estratégia de legitimação, dentro dos processos de estruturação e institucionalização dos campos organizacionais. Como argumentam Elsbach e Sutton (1992, p.700), "um maior entendimento de como as organizações adquirem e protegem a legitimidade pode ser obtido através da combinação entre as perspectivas institucional e de gerenciamento de impressões".

As estratégias e táticas de gerenciamento de impressões se inserem, junto com as ações de comunicação corporativa, num processo de construção da imagem corporativa que visa a legitimação da organização em relação ao seu ambiente técnico institucional (MENDONÇA e ANDRADE, 2002).

O gerenciamento de impressões tem sido visto com reservas no meio acadêmico, já que é comumente associado a ações manipulativas e à falsidade. Ramos (1982) o reconhecia na política cognitiva, ou seja, no uso consciente de uma linguagem distorcida, cuja finalidade é levar as pessoas a interpretarem a realidade em termos adequados aos interesses dos agentes diretos e/ou indiretos de tal distorção.

Wood (2001) vê a passagem do mundo pré-moderno - onde trabalho e produto formavam um todo indivisível e, portanto, interligavam substância com imagem - para o mundo contemporâneo - onde a ação substantiva dá lugar à manipulação da imagem - relacionada às mudanças culturais e ao aumento da complexidade e turbulência dos novos tempos. Nestes novos tempos, de afastamento entre os aspectos materiais e culturais da experiência humana, e de fragmentação das conexões entre essas instâncias, os símbolos servem como pontes, tornando administráveis a distância entre eles e a ambigüidade inerente à situação. 
A comunicação simbólica tem lugar na organização, por meio da complexa rede informal de comunicação que permeia os processos decisórios - a tessitura organizacional. Para evitar interpretações e ambigüidades, é fundamental criar visões compartilhadas. A linguagem, nesse caso, assume função persuasiva, retórica, orientada para a construção de significados. O exercício do poder justificaria a adoção do gerenciamento de impressões e da comunicação simbólica. Segundo Pfeffer (1981),

"a função daqueles que desejam exercer poder nas organizações é apresentar as decisões e atividades de uma maneira expressiva e sensível para os membros da organização, de forma que o consenso social e as definições sociais ao redor dessas atividades e decisões possam se desenvolver".

De uma perspectiva mais ampla, as autoridades públicas, no exercício do poder conferido pelo mandato eletivo, devem buscar o consenso da sociedade para suas decisões. Uma forma de estabelecer essa comunicação se verifica pelo exercício dos mecanismos de gerenciamento de impressões. No caso do Banco Central do Brasil, o estabelecimento de uma postura ativa em relação ao mercado financeiro vem construindo uma imagem de respeitabilidade e coerência com os objetivos do governo, valendo-se da competência técnica de seus quadros para consolidar um mito muito caro para uma organização pública, que é o da eficácia de suas ações.

\section{0 mito da eficácia do Banco Central do Brasil}

A história do desenvolvimento econômico revela um quadro marcado por conquistas - tanto no plano diplomático quanto militar - que visavam o domínio e a expansão dos mercados. A cultura dos povos sempre sublimou essas conquistas como a realização da capacidade das nações, valorizando elementos simbólicos como forma de desenvolvimento de uma identidade nacional, alinhando assim os interesses individuais à consecução das metas estabelecidas pelos governos aos respectivos Estados.

Um dos mitos mais marcantes nas sociedades ocidentais é o do mercado, uma entidade invisível que permeia o tecido social e faz com que a sociedade se desenvolva centrada em torno do mito. Como ensina Ramos (1982),

"A motivação econômica é considerada o traço supremo da natureza humana e a teoria econômica formal afirma que o mercado é a categoria fundamental para a comparação, a avaliação e o desenho dos sistemas sociais. (...) Essa perspectiva sugere que os países do Terceiro Mundo só poderão resolver seus problemas se se transformarem em sociedades centradas no mercado".

Assim, a própria ciência social acaba legitimando o mito, ao afirmar a primazia da atividade econômica sobre os outros aspectos da vida social, da vida social como padrão normativo e dos valores econômicos sobre os valores humanos.

Em contraposição ao mito do mercado, os Estados desenvolvem o mito da autoridade, de sua capacidade de impor a decisão coletiva dos indivíduos sobre as forças movidas pelos interesses econômicos. As sociedades ocidentais, na formação dos Estados nacionais, procuram estabelecer o disciplinamento e o controle sobre o fluxo de capitais, visando fundamentalmente ao financiamento de suas despesas, já que esses capitais já não se encontram mais em poder do Estado, mas dispersos nas mãos de grupos capitalistas privados. A forma predominante de exercer esse controle é através do estabelecimento de uma entidade representativa dessa autoridade, o Banco Central, a quem cabe também financiar as despesas governamentais, através da emissão de papel moeda. No desenvolvimento dessas entidades, agregam-se as forças representativas do poder econômico, que têm interesse no papel exercido pelo Banco Central como emprestador de última instância e financiador de linhas de crédito, com recursos provenientes do Tesouro Nacional. Nesse desenvolvimento, evoluem concepções que atribuem maior ou menor poder e autonomia a essas entidades, mas em todas, o Banco Central assume o papel de autoridade monetária e desenvolve o mito de sua atuação coordenadora, muitas vezes intervencionista, no estabelecimento de volumes de emissão de papel moeda, da taxa referencial de juros, da taxa de câmbio com outras moedas, e da taxa dos depósitos compulsórios das instituições financeiras sobre seus depósitos à vista. 
O Banco Central do Brasil tem desenvolvido, desde sua criação como autoridade monetária do país, em 1964 em substituição à Superintendência da Moeda e do Crédito do Ministério da Fazenda, ao Banco do Brasil e ao Tesouro Nacional, que dividiam essas competências - o mito da eficácia nas decisões que lhe competem, reforçando sua credibilidade junto aos demais agentes públicos e privados atuantes no sistema financeiro, bem como à sociedade em geral. Neste artigo, é defendida a idéia de que essa atuação é consciente da necessidade de legitimação pela sociedade do papel que lhe foi conferido, numa estratégia que pretende garantir a sobrevivência da instituição pela legitimidade alcançada, em conformidade com a perspectiva institucional (MEYER e ROWAN, 1977; DiMAGGIO e POWELL,1983). Nesse caso, predomina o ambiente institucional "o conjunto de normas e exigências ao qual as organizações devem se conformar, se querem obter apoio e legitimidade do ambiente" (SCOTT, 1992, p.157) - sobre o ambiente técnico, onde se exerce controle sobre a produção das organizações. É reconhecida a assertiva defendida pelos institucionalistas de que a incorporação pelas organizações das práticas e procedimentos definidos nos conceitos de racionalidade institucionalizados pela sociedade se dá na expectativa que essas organizações têm de angariar legitimidade - na forma de apoio cultural, moral e político - que a sociedade confere (MEYER e ROWAN, 1977).

A manipulação simbólica se manifesta de formas variadas, que em comum buscam o estabelecimento da imagem de uma permanente confrontação entre as forças do mercado e o poder disciplinador do Banco Central. A forma mais visível dessa confrontação se manifesta nas disputas diárias no mercado de câmbio, que refletem inequivocamente o simbolismo das atitudes das partes envolvidas: de um lado, as forças invisíveis do mercado, que sensíveis aos mais diversos fatos, carregados de valores que muitas vezes suplantam a racionalidade, tendem a empurrar a taxa a valores progressivamente depreciados; enquanto, de outro lado, os paladinos da racionalidade e do bom senso, encarnados nas figuras do presidente do Banco Central e seus diretores, injetam recursos, financeiros ou simbólicos, na manutenção da paridade das moedas nacional e alienígena. O discurso é uma das ferramentas mais significativas nessa luta, e a eles a nação recorre, na tentativa de estabelecer um clima de confiança que acalme o "nervosismo" do mercado. Esse discurso é carregado de significados, pois revela - na mesma proporção em que sinaliza a presença de um agente do Estado disposto a normatizar as relações entre os atores sociais, - a existência de forças que se pretende controlar, a partir do estabelecimento de acordos tácitos, simbólicos, que se reflitam em comportamentos no sentido ditado pelos detentores do poder político e econômico.

Outras arenas de confrontação são estabelecidas, e nelas o embate acontece de forma mais sutil. Os dirigentes estatais parecem ter noção da natureza do mito, pois têm estabelecido a regularidade como substituta da intempestividade que esteve presente e caracterizou os anos anteriores ao Plano Real. O estabelecimento das taxas referenciais de juros, por exemplo, é hoje feito a intervalos regulares de tempo, com uma sinalização de tendência que a autoridade monetária prevê, num ritual que institucionaliza o poder simbólico através das reuniões do Comitê de Política Monetária - o Copom.

De forma semelhante, a intervenção direta no sistema financeiro vem sendo gradualmente substituída por formas de controle mais difusas, menos perceptíveis porque internalizadas. Assim é que na supervisão do sistema financeiro têm sido adotadas práticas preventivas em lugar das repressivas, reforçando, pela atribuição de responsabilidade solidária às instituições financeiras no controle e coibição de atividades ilícitas e irregulares, o mito da onipresença do controle do Estado.

A última diretoria do Banco Central no governo Fernando Henrique Cardoso, e muito particularmente seu presidente, reforçaram com sua atuação e suas características pessoais, mitos de eficácia inquestionáveis. A imagem do então presidente do banco, Armínio Fraga, foi construída com base na grande capacitação técnica, na sólida formação acadêmica e na comprovada competência, por já ter atuado como executivo de instituição financeira representante das forças do mercado. Essa imagem positiva foi reforçada pelas atitudes equilibradas e pleno domínio dos instrumentos simbólicos, como a retórica e a gerência de impressões. Assim, ao final daquele governo, Armínio Fraga era considerado figura inatacável, tanto que, mesmo a oposição tendo ganho as eleições presidenciais, foi cogitada sua permanência no cargo. 
Sua atuação no governo reforçou o mito. Quando assumiu o cargo, o país passava por dificuldades derivadas da centralização do câmbio, que foi flexibilizado. Armínio Fraga manteve um discurso afinado com a manutenção da estabilidade e vendeu a imagem do trabalhador incansável, engajado numa missão que traduzia como possível, reduzindo sua complexidade. Demonstrou capacidade de rápida compreensão da dinâmica do mercado, e soube estabelecer a comunicação simbólica com esses setores, sinalizando com a taxa de juros a construção de significados. Seu posicionamento técnico, apartidário, foi fundamental para a consolidação da imagem de austeridade e de compromisso institucional.

Dessa forma, dentro do espaço simbólico do sistema econômico nacional, o Banco Central do Brasil reafirmou sua posição de liderança no campo e consolidou a legitimação pela sociedade. Embora sua atuação ainda sofra questionamentos, a estratégia conduzida pela atual diretoria foi bem sucedida nos aspectos de comunicação e liderança simbólicas, gerenciando de maneira eficaz a imagem da instituição, o que resultou no reconhecimento pela sociedade da eficácia na condução da política monetária.

\section{Conclusões}

A realidade vivida pela sociedade brasileira nos dá evidências para que, com base na teoria do poder simbólico, haja uma explicação para a atuação dos diversos agentes envolvidos com a política econômica do país. Este artigo procurou identificar os elementos que formam a imagem de eficácia do Banco Central do Brasil, e de que forma tais elementos são manipulados nesse sentido.

A utilização de instrumentos simbólicos pelos seus dirigentes foi associada ao estabelecimento de comunicação entre a organização e seu ambiente institucional, de forma a compartilhar valores e assimilar suas exigências. É verificado que, desde a criação do Banco Central do Brasil, a instituição identificou no gerenciamento de impressões um instrumento a ser utilizado na construção da imagem de autoridade monetária eficaz, canalizando recursos do ambiente institucional que garantam a sobrevivência da organização.

O processo de legitimação aparece tanto nas estratégias e nas ações desenvolvidas, em que representa o objetivo final do gerenciamento de impressões, quanto na consolidação do poder de quem se utiliza desses mecanismos. Assim, do reconhecimento do poder como fenômeno consensual (PARSONS, 1960) deriva a necessidade de legitimação, que tem no gerenciamento de impressões uma forma de conquistá-la. $O$ dirigente público consolida sua liderança, e conseqüentemente seu poder, quando exerce de forma eficaz a comunicação simbólica com seu público-alvo, que inclui a organização, a classe política e a sociedade em geral.

Nesse sentido, a abordagem institucional da teoria das organizações contribui para explicar a motivação das organizações públicas em desenvolver mecanismos simbólicos. Ao ampliar o conceito de ambiente para além dos fluxos e intercâmbios técnicos, é explicitado o "locus" onde a atuação da organização pública é avaliada e onde ela obtém recursos para sua manutenção.

A estratégia adotada pelo Banco Central do Brasil em relação a seu público externo, traduzida por ações características de gerenciamento de impressões, teve efeito positivo na condução das políticas públicas sob sua responsabilidade. Por sua relevância, é sugerido o aprofundamento desse tema, seja em sua conceituação, seja através de estudos empíricos, com exemplos que concorram para a avaliação dos modelos que se propõem a explicar a aquisição de legitimidade pelas organizações. 


\section{Referências bibliográficas}

ARENDT, H. Sobre a violência. Rio de Janeiro: Relume-Dumará,1994.

BACHRACH, P.; BARATZ, M. S. Power and poverty: theory and practice. Oxford: Oxford University Press, 1970.

BENNIS, W. G., et al. Authority, power and the ability to influence. Human Relations, v.11, n.2, p.14-156, 1958.

BOURDIEU, P. The state mobility: elite schools in the field of power. Stanford: Stanford University Press, 1996.

0 poder simbólico. 3. ed. Rio de Janeiro: Bertrand do Brasil, 2000.

BURRELL, G; COOPER, R. Modernism, postmodernism and organizational analysis: an introduction. Organization Studies, v.9, n.1, p.91$112,1988$.

CALÁS, M. B.; MacGUIRE, J. B. Organizations as networks of power and symbolism. In: Turner, B. A. Organizational symbolism. Berlin: Walter de Gruyter, 1990.

CARVALHO, C. A.; VIEIRA, M. M. F.; LOPES, F. D. Contribuições da perspectiva institucional para a análise das organizações. In: ENCONTRO ANUAL DA ANPAD, 23., Foz do Iguaçu, 1999. Anais..., Foz do Iguaçu: Anpad, 1999. CD-ROM.

CROZIER, M . 0 fenômeno burocrático: ensaio sobre as tendências burocráticas dos sistemas de organização modernos e suas relações, na França, com o sistema social e cultural. Brasília: Editora UnB, 1981.

DANDRIDGE, T. C.; MITROFF, I.; JOYCE, W. F. Organizational symbolism: a topic to expand organizational analysis. Academy of Management Review, v.5, n.1, p.77-82, 1980.

DURKHEIM , Émile. Da divisão do trabalho social. S.Paulo: Martins Fontes, 1999.

ELSBACH, K. D.; SUTTON, R. I. Acquiring organizational legitimacy through illegitimate actions: a marriage of institutional, and impression management theories. Academy of Management Journal. v.35, n.4, p. 699-738, 1992.

DiMAGGIO, Paul J ., POWELL, Walter W. The iron cage revisited: institutional isomorphism and collective rationality. American Sociological Review, n.48, p.147-160, 1983.

FOUCAULT, M. Discipline and punish: the birth of the prison. Harmondsworth: Penguin, 1977.

HARDY, C.; CLEGG, S. Alguns ousam chamá-lo de poder. In: CLEGG, S.; HARDY, C.; NORD, W. (Orgs.). Handbook de Estudos Organizacionais. São Paulo: Atlas, 1999. v.2, p.260-289.

LUKES, S. Poder e autoridade. In: BOTTOMORE, T.; NISBET, R. História da análise sociológica. Rio de Janeiro: Francisco Alves, 1983.

LYOTARD, J-F. A condição pós- moderna. 5. ed. Rio de Janeiro: José Olympio, 1998.

MENDONÇA, J. R.; ANDRADE, J. A. Teoria institucional e gerenciamento de impressões: em busca da legitimidade organizacional através do gerenciamento da imagem corporativa. In: ENCONTRO NACIONAL DE ESTUDOS ORGANIZACIONAIS, 2., Recife, 2002. Anais... Recife: Eneo, 2002.

MEYER, J. W.; ROWAN, B. Institutionalized organizations: formal structures as myth and ceremony. American Journal of Sociology, n.83, p.340-363, 1977.

MINTZBERG, H. Power in and around organizations. Englewood Cliffs: Prentice-Hall, 1983.

MISOCZKY, M. C. Poder e institucionalismo: uma reflexão crítica sobre as possibilidades de interação paradigmática. 2002. (Versão revisada de "Campo de poder e ação em Bourdieu: implicações de seu uso em estudos organizacionais". In: ENCONTRO ANUAL DA ANPAD, 25., Campinas, 2001. Anais... Campinas: Anpad, 2001.)

PARSONS, T. Structure and process in modern societies. New York: Free Press, 1960.

PETTIGREW, A. M. Strategy formulation as a political process. International Studies of Management and Organizations, v.7, n.2, p.78-87, 1977.

PFEFFER, J. Power in organizations. Cambridge: Ballinger, 1981.

RAM OS; A. G. A nova ciência das organizações: uma reconceituação da riqueza das nações. Rio de Janeiro: FGV, 1982.

SCOTT, R. Organizations: rational, natural and open systems. Englewood Cliffs: Prentice-Hall, 1992.

; MEYER, J. Institutional environments and organizations: structural complexity and individualism. London: Sage, 1994.

Symbols and organizations: from Chester Barnard to the institutionalists. In: WILLIAMSOM, O. (Ed.). Organization theory: from Chester Barnard to the present and beyond. Oxford: Oxford University Press, 1995a.

; CHRISTENSEN, S. The institutional construction of organizations. London: Sage, 1995b. 
SELZNICK, P.. TVA and the grass roots. Berkeley: University of California Press, 1949.

. Leadership in administration. New York: Harper and Row, 1957.

SMIRCICH, L.; MORGAN, G. Leadership: the management of meaning. The Journal of Applied Behavioral Science, v.8, n.3, p.257-273, 1982.

THOM PSON, J. D. Authority and power in identical organizations. American Journal of Sociology, v.62, p.290- 301, 1956.

VIEIRA, M. M. F.; MISOCZKY, M. C. Instituições e poder: explorando a possibilidade de transferências conceituais. In: ENCONTRO NACIONAL DE ESTUDOS ORGANIZACIONAIS, I., Curitiba, 2000. Anais... Curitiba: Eneo, 2000.

; CARVALHO, C. A.; LOPES, F. D. The structuring of the organizational field of theaters and museums in the south of Brazil. In: EUROPEAN GROUP FOR ORGANIZATION STUDIES COLLOQUIUM, 17., Lyon-France, 2001. Anais... Lyon- France, 2001.

WEBER, M. Economia y sociedad. México: Fondo de Cultura Económica, 1997.

WOOD Jr., T. Organizações espetaculares. Rio de J aneiro: FGV, 2001. 